\title{
Complications and reoperations of the SB Charité lumbar disc prosthesis: experience in 75 patients
}

\author{
Ilona M. Punt • Violette M. Visser · Lodewijk W. van Rhijn · Steven M. Kurtz • \\ Jop Antonis · Geert Willem H. Schurink · André van Ooij
}

Received: 27 April 2007/Revised: 29 August 2007/Accepted: 17 September 2007/Published online: 10 October 2007

(C) Springer-Verlag 2007

\begin{abstract}
Artificial disc prosthesis show fair to good short- and mid-term results. Long-term results are becoming apparent now, however, the incidence of late complications with this procedure remain poorly understood. In this report we will analyse late complications and discuss our experiences with salvage operations in patients with persistent pain after SB Charité disc prosthesis implantation. Seventy-five patients with persistent leg and back pain after insertion of an artificial disc prosthesis were enrolled in the study. In this negative selection frequently occurring late-complications were subsidence, wear, adjacent disc degeneration, facet joint degeneration and migration. In 15 patients we performed a posterior fusion without disc removal, and in 22 patients we removed 26 prostheses and performed a posterior and anterior fusion. The visual analogue scale (VAS) and Oswestry were examined before the salvage operation and after a followup period of at least 1 year, which is not yet available in all patients. The VAS and Oswestry decreased in the posterior group $(n=10)$ respectively from 8.0 (SD 0.9$)$ to $6.3(\mathrm{SD}$
\end{abstract}

I. M. Punt · V. M. Visser - L. W. van Rhijn - J. Antonis ·

A. van Ooij ( $\square)$

Department of Orthopaedic Surgery, University Hospital

Maastricht, Postbox 5800, 6202 AZ Maastricht, The Netherlands

e-mail: avoo@sort.azm.nl

S. M. Kurtz

Drexel University and Exponent, Inc., 3401 Market Street,

Suite 300, Philadelphia, PA 19104, USA

G. W. H. Schurink

Department of Vascular Surgery,

University Hospital Maastricht,

Maastricht, The Netherlands
2.1) and from 57.0 (SD 17.0) to 44.6 (SD 20.4); and in the disc removal group $(n=14)$ respectively from 8.0 (SD 0.9) to 5.6 (SD 2.7) and from 56.3 (SD 14.0) to 43.0 (SD 20.7). Serious late complications may occur following total disc replacement. Removal of the SB Charite artificial disc is feasible but with inherent risks. Removal of the disc prosthesis gives slightly better results than posterior fusion alone after a follow-up of at least 1 year.

Keywords Artificial disc - Retrieval surgery · Risk of reoperation · Complications

\section{Introduction}

Degenerative disc disease (DDD) is a major cause of pain and disability, with great social and financial impact, playing an increasing role in modern society [21]. Several surgical techniques have been developed to treat DDD. Spinal fusion is seen as the "gold standard", but nowadays artificial disc prostheses are an alternative method [13]. The artificial disc should preserve motion, stability and normal function of a spinal segment. Also, less adjacent segment degeneration is expected $[6,7,13,15]$. In theory, this procedure has many advantages over spinal fusion. A spinal fusion does eliminate motion and can cause overloading and early degeneration of the adjacent levels, although usually appearing only after $10-15$ years $[1,11$, 12, 17].

Results after implantation of the SB Charite artificial disc prosthesis are diverse. short- and mid-term results are fair to good [3, 5, 13, 22]. The FDA-IDE study, in which the SB Charité artificial disc was tested for approval in the US, showed a FDA-defined, overall clinical success rate of $57.1 \%$ after 2-year follow-up [2, 15]. For the IDE study, 
the procedure was only judged to be successful if four criteria were satisfied: (1) greater than $25 \%$ improvement in Oswestry disability index; (2) no device failure; (3) no major complications; and (4) no neurological deterioration compared to preoperative status. Consequently, the composite definition of success employed in the IDE study makes it difficult to compare with other studies that employed different success criteria.

In a 10-year follow-up period, Lemaire et al. [13] found that $90 \%$ of patients had good to excellent clinical outcome. On the other hand, in the only available long-term study of Putzier et al. [16] with an average follow-up of 17 years, the investigators found no evidence that longterm results of the disc prosthesis were superior to spinal fusion [16]. It remains unclear whether the early fair to good results obtained with an artificial disc will be consistently maintained with a longer follow-up period $[9,16$, $18,20]$.

In the Netherlands, more than 1,000 patients have been implanted with a SB III Charité (Link, Germany) disc prosthesis starting in 1989. As these patients received the implant during routine clinical practice, they were not the subjects of a randomized trial. However, 50 patients (75 arthroplasties) were enrolled in a prospective observational trial, and at 2 years the clinical success rate was found to be $70 \%$ [22].

Since 1989, there have been many changes in the available implant sizes, surgical instrumentation, and patient indications. Although the basic "SB III" design has remained the same throughout the past 18 years, there have also been evolutionary changes in the polyethylene (PE) resin, sterilization, and endplate fixation technology. Starting in 2004, the SB III design has been renamed the Charité artificial disc and is currently produced by a different manufacturer (DePuy Spine, Raynham, MA, USA). Despite these aforementioned changes, it remains crucially important to fully understand the long-term clinical failure modes of early total disc replacements, as they form the foundation for judging the performance of contemporary implant designs and treatment paradigms.

At present, we have treated 75 patients at our clinic with persistent leg and back pain after insertion of the SB Charité disc prosthesis. The incidence of complications following Charité artificial disc implantation at our institution has proven difficult to deduce because all operations were performed elsewhere. At 2 years of follow up, investigators from the hospital implanting the disc prosthesis reported that 17 out of $50(34 \%)$ patients required secondary surgery, and there were three $(6 \%)$ reported serious complications [22]. The purpose of this study is to analyse late-complications after insertion of a disc prosthesis, and to describe our experiences with salvage operations in this difficult patient group.

\section{Materials and methods}

\section{Patients}

Approximately more than 1,000 Dutch patients, suffering from serious and constant back and leg pain, have been implanted with a SB III Charité (Link, Germany) artificial disc prosthesis in the lower lumbar spine.

Over the last 10 years, 75 patients of this cohort, with persisting back and leg pain and being unsatisfied with their clinical situation, were seen at the orthopaedic outpatient clinic of the University Hospital of Maastricht (UHM). They were seen by a different orthopaedic surgeon ( AvO and LvR) than the surgeon who performed the prosthesis implantation. Twenty-seven of these cases have already been reported previously [20].

Forty-one patients were female with an average age at the time of disc implant of 42 years and 7 months (3063 years) and 34 patients were male with an average age of 40 years and 9 months (30-51 years) at the time of disc implant (Table 1). The operated levels and the year the patients received their artificial disc implantation is shown in Table 1.

Forty-six out of these 75 patients needed one or more salvage operations after their artificial disc implant. Indicators for reoperations were primary absence of pain relief, new pathology according to radiography, CT-scan or MRI in adjacent segment(s), subsidence, facet joint arthrosis or migration of the prosthesis. In our hospital, we performed posterior fusion in 15 patients without disc removal, and in

Table 1 Patient characteristics

\begin{tabular}{lrl}
\hline Sex & $N$ & Age at artificial disc insertion \\
\hline Males & 34 & 40 years and 9 months (30-51) \\
Females & 41 & 42 years and 7 months (30-63) \\
Operated level & & \\
First level & & \\
L2-L3 & 3 & \\
L3-L4 & 22 & \\
L4-L5 & 30 & \\
L5-S1 & & \\
Second levels & 1 & \\
L3-L4, L5-S1 & 16 & \\
L4-L5, L5-S1 & \\
Third levels & 1 & \\
L3-L4, L4-L5, L5-S1 & \\
L2-L3, L4-L5, L5-S1 & 1 \\
Time disc implantation & \\
1989-1994 & 25 \\
1995-1999 & 30 \\
2000-2005 & 20 \\
\hline
\end{tabular}


22 patients we removed 26 prostheses and performed an anterior and posterior fusion. In addition, seven patients received posterior fusion elsewhere, and in two patients the disc prosthesis was removed elsewhere (Fig. 1).

\section{Surgical method of disc prosthesis removal}

The disc prosthesis was removed by a team consisting of a vascular surgeon and an orthopaedic surgeon. The patient was placed under general anaesthesia and positioned in supine position (for level L5-S1) or in a semilateral position (for level L4-5 or higher).

A disc prosthesis at level L4-5 was removed via anterolateral lumbotomy, without mobilisation of the great vessels. A disc prosthesis at level L5-S1 was removed through the original left retroperitoneal approach or alternatively via right retroperitoneal, between the great vessels. To remove the disc prosthesis one of the endplates was released by undercutting and removal of some bone after cleaning of fibrous tissue. The metal endplate was gripped and removed with twisting and pulling manoeuvres. Then the core and second endplate was easily released and removed.

The gap between the vertebral bodies after retrieval of the disc prosthesis was mostly $2.5-3 \mathrm{~cm}$ high. This was filled with an autologous strut graft in 2 patients, artificial bone in 3 patients and allograft strut grafts and allograft bone chips from femoral heads in 17 patients. We now favour the insertion of allograft strut grafts from the bone bank.

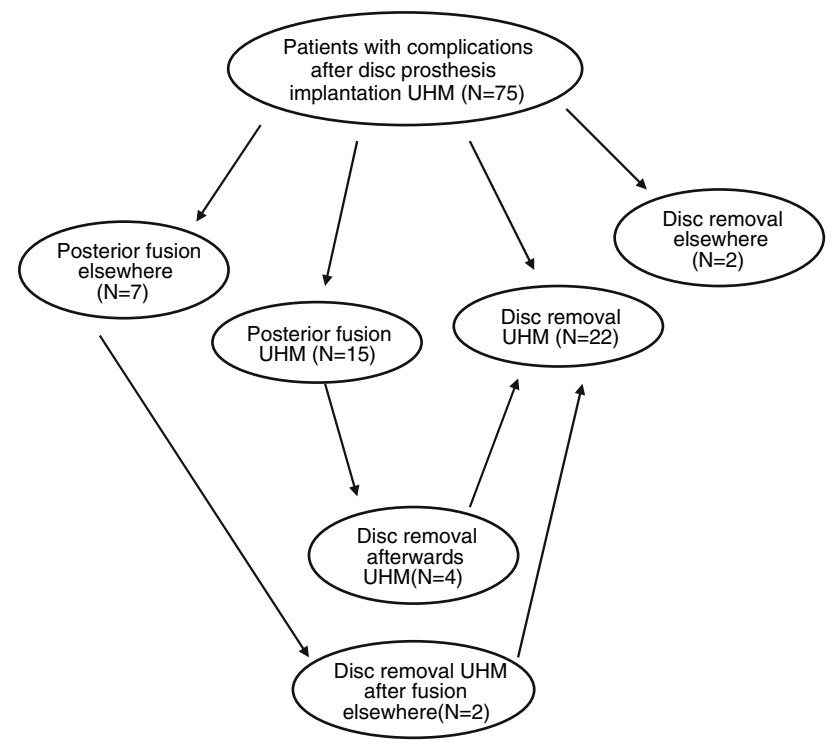

Fig. 1 Overview of reoperations after disc prosthesis implantation (UHM: University Hospital Maastricht)
Clinical performance and complications

Before the orthopaedic surgeons in our outpatients clinic performed reoperation, they evaluated the images of X-ray, CT-scans, MRI and if necessary discography on the presence of late complications.

Clinical examination included the ten-point visual analogue scale (VAS), ranging from 0 points for "no pain" and 10 points for "severe pain", and the Oswestry low back pain disability questionnaire. The VAS and Oswestry were examined before the salvage operation and after a follow-up period of at least 1 year after this operation. The 1 year follow-up VAS and Oswestry are not yet available in all patients.

\section{Statistical analysis}

Analyses were performed using SPSS, release 12.0.1. Nonparametric tests, i.e. Mann-Whitney and Wilcoxon, were used to test mean. Significance was indicated by $P$ values less than 0.05 .

\section{Results}

\section{Late complications}

An overview of late complications after disc implantation is shown in Table 2. They included the following: 39 patients showed subsidence of the disc prosthesis, in 24 of these patients the disc prosthesis was considered too small. Thirty-six patients showed signs of adjacent disc degeneration, narrowing of the disc and osteophytes on conventional X-rays. In 17 patients this was not obvious before artificial disc insertion on plain $\mathrm{X}$-rays and

Table 2 Overview of late complications after receiving a disc prosthesis (patients can have more than one complication)

\begin{tabular}{ll}
\hline Late complications & Number of patients \\
\hline Subsidence & 39 \\
Disc prosthesis too small & 24 \\
Adjacent disc degeneration & 36 \\
Degenerative scoliosis & 11 \\
Facet joint degeneration on CT scan & 25 \\
Anterior migration & 6 \\
Posterior migration & 2 \\
Breakage metal wire & 10 \\
Wear & 5 \\
Severe osteolysis & 1 \\
Subluxation PE core & 1 \\
\hline
\end{tabular}




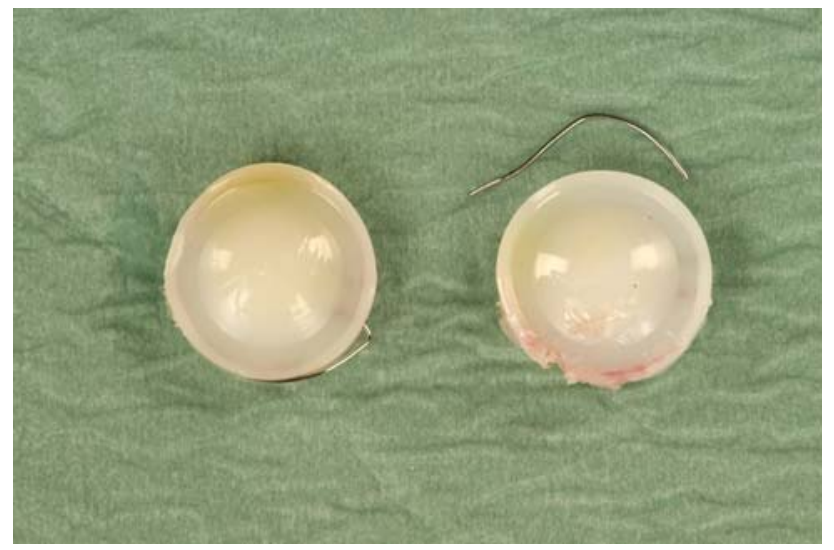

Fig. 2 Example of removed polyethylene core L4-5 (left) and L5-S1 (right) (6.5 years after insertion) with a fracture of the metal wire and damage of disc prosthesis

discography. Eleven patients with multi-level adjacent disc degeneration had developed degenerative lumbar scoliosis. In 25 patients facet joint degeneration was seen on CTscans. In six patients the disc prosthesis showed anterior migration and in two patients posterior migration of the disc prosthesis occurred. In ten patients we discovered breakage of the metal wire around the core (Fig. 2).

Less often the surgeons noticed the subsequent late complications. In one case severe osteolysis was seen in the sacrum in a ruptured and severely worn L5-S1 case. In another case a subluxation of the PE core and an adjacent osteoporotic compression fracture was noticed. In five patients radiological wear of the disc prosthesis was obvious due to loss of height of the core, or sclerosis and cysts around the prosthesis on CT-scan.

\section{Study population}

The group of 15 patients receiving posterior fusions in our hospital without removing the prosthesis, consisted of 8 men and 7 women. Mean age at their revision surgery was 49 years and 9 months (34-76 years) and mean timeinterval between their disc implant and revision surgery was 7 years and 11 months (2-15 years).

Facet joint degeneration was noticed during all operations. Afterwards, we removed the disc prosthesis in four patients of this group because of persisting pain. Nowadays, we advise disc prosthesis removal in conjunction with fusion surgery, assuming that the disc prosthesis can remain a pain source even after solid posterior fusion.

So far, we retrieved 26 prostheses in 22 patients (17 females, 5 males). The additional posterior fusion took place in nine patients 2 weeks before or 2 weeks after the removal of the disc prosthesis. In the other 13 patients, posterior fusion was done as a second operation on the

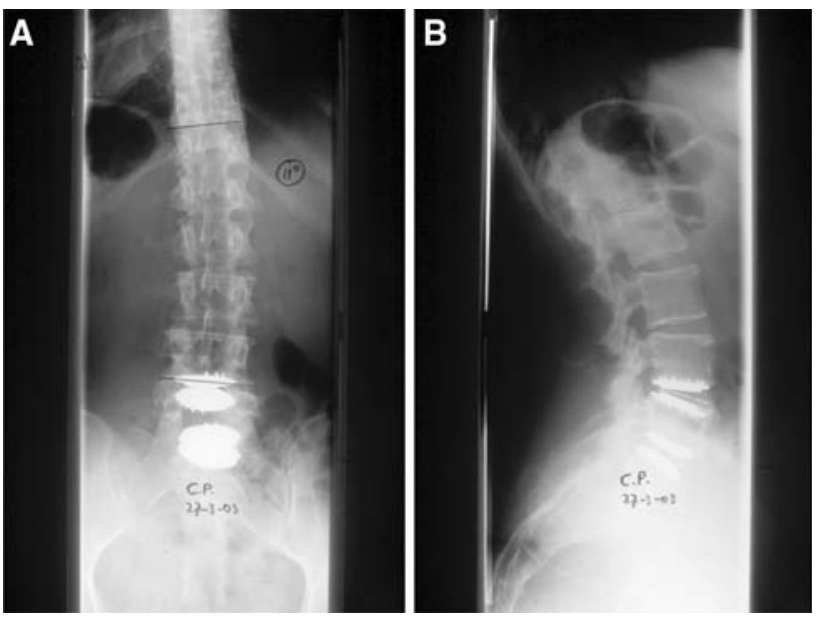

Fig. 3 a Anteroposterior and $\mathbf{b}$ lateral radiograph of the lumbar spine 3 years and 9 months after disc replacement at L4-5 and L5-S1

same day as the removal. Nowadays this is the standard procedure in our hospital. The mean interval between insertion and retrieval of the disc prosthesis was 8 years and 11 months (3-16 years). The mean age at retrieval of the disc prosthesis was 50 years (40-72 years).

A pre- and post-operative radiograph of one case, in which we removed the disc prosthesis L4-5 and L5-S1 and performed a posterior and anterior fusion, is shown in Figs. 3 and 4.

Intraoperatively we twice encountered a lesion of the left common iliac vein (in L5-S1 cases), once a lesion of

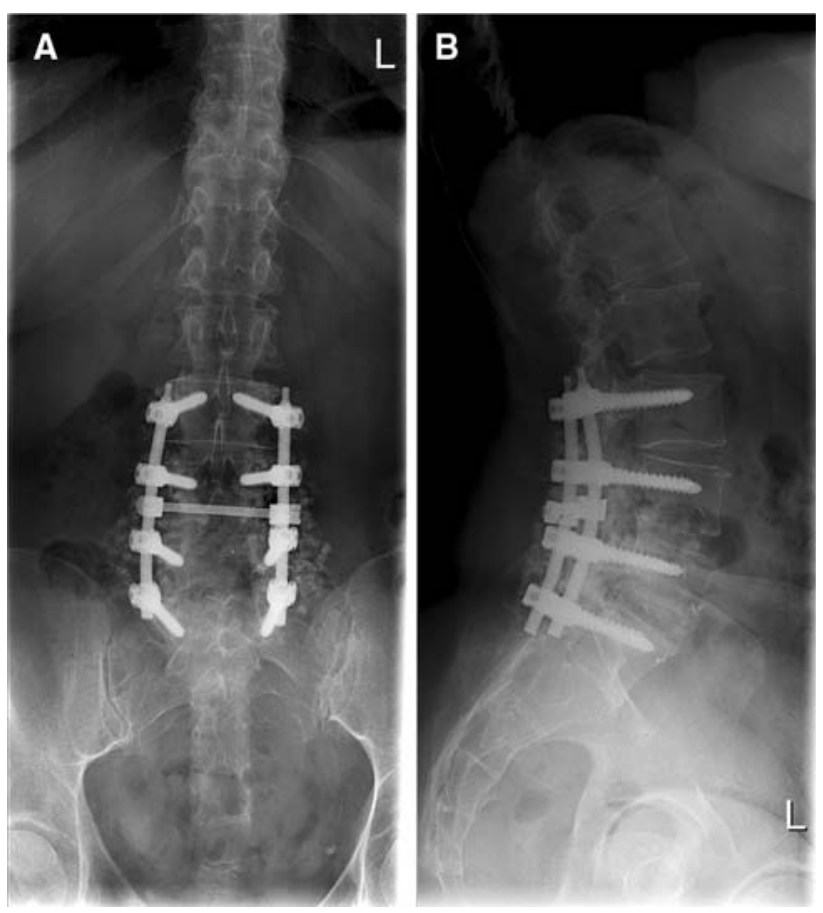

Fig. 4 a Anteroposterior and $\mathbf{b}$ lateral radiograph of the lumbar spine 9 months after revison surgery 
Table 3 Clinical information for both revision strategies (with a follow-up period of at least 1 year)

\begin{tabular}{|c|c|c|c|c|c|c|c|c|c|c|}
\hline $\mathrm{Nr}$ & Sex & $\begin{array}{l}\text { Year } \\
\text { index } \\
\text { surgery }\end{array}$ & $\begin{array}{l}\text { Age index } \\
\text { surgery }\end{array}$ & Levels & $\begin{array}{l}\text { Year } \\
\text { re-operation }\end{array}$ & $\begin{array}{l}\text { Removal/ } \\
\text { fusion }\end{array}$ & $\begin{array}{l}\text { Extra } \\
\text { procedures }\end{array}$ & $\begin{array}{l}\% \\
\text { improvement } \\
\text { VAS }\end{array}$ & $\begin{array}{l}\% \\
\text { improvement } \\
\text { Oswestry }\end{array}$ & $\begin{array}{l}\text { Clinically } \\
\text { improved } \\
\text { Oswestry }(>25 \%)\end{array}$ \\
\hline 1 & $\mathrm{~F}$ & 1993 & 44 & L2-L3 & 2003 & Fusion & None & 41.18 & 27.50 & Yes \\
\hline 2 & M & 1995 & 41 & L4-L5 & 1997 & Fusion & None & -33.33 & -44.44 & No \\
\hline 3 & $\mathrm{~F}$ & 1992 & 63 & L5-S1 & 2005 & Fusion & None & -14.29 & -24.34 & No \\
\hline 4 & M & 1997 & 30 & L5-S1 & 2001 & Fusion & None & 27.78 & 16.67 & No \\
\hline 5 & $\mathrm{~F}$ & 2000 & 42 & L4-L5 & 2003 & Fusion & None & 12.50 & 14.71 & No \\
\hline 6 & $\mathrm{~F}$ & 1996 & 42 & L4-L5, L5-S1 & 2003 & Fusion & None & 27.78 & 6.45 & No \\
\hline 7 & $\mathrm{~F}$ & 2002 & 38 & L4-L5, L5-S1 & 2003 & Fusion & None & 29.41 & 16.13 & No \\
\hline 8 & M & 1997 & 48 & L5-S1 & 2004 & Fusion & None & 86.67 & 82.76 & Yes \\
\hline 9 & M & 1995 & 37 & L5-S1 & 2005 & Fusion & None & 18.75 & 0.00 & No \\
\hline \multirow[t]{2}{*}{10} & $\mathrm{~F}$ & 1997 & 34 & L5-S1 & 2002 & Fusion & None & 0.00 & 74.07 & Yes \\
\hline & & & & & 2005 & Removal & None & 29.41 & Missing & Missing \\
\hline 11 & M & 1992 & 37 & L4-L5 & 2005 & Removal & None & -12.50 & 25.00 & Yes \\
\hline 12 & $\mathrm{~F}$ & 1995 & 33 & L4-L5 & 2006 & Removal & None & -12.50 & 5.41 & No \\
\hline 13 & $\mathrm{M}$ & 1989 & 44 & L4-L5 & 2005 & Removal & None & 12.50 & 30.00 & Yes \\
\hline 14 & $\mathrm{~F}$ & 1991 & 39 & L4-L5 & 2002 & Removal & None & 87.50 & 56.25 & Yes \\
\hline 15 & $\mathrm{~F}$ & 1995 & 39 & L5-S1 & 2004 & Removal & None & 76.47 & 73.08 & Yes \\
\hline 16 & $\mathrm{~F}$ & 1999 & 46 & L4-L5, L5-S1 & 2005 & Removal & None & 62.50 & 62.50 & Yes \\
\hline 17 & $\mathrm{~F}$ & 1992 & 33 & L3-L4, L5-S1 & 2005 & Removal & None & 11.11 & 12.50 & No \\
\hline 18 & M & 1998 & 46 & L4-L5 & 2004 & Removal & None & 9.09 & 38.10 & Yes \\
\hline 19 & $\mathrm{~F}$ & 1992 & 32 & L2-L3, L4-L5, L5--S1 & 2004 & Removal & None & 55.56 & 16.80 & No \\
\hline 20 & M & 2001 & 47 & L4-L5 & 2005 & Removal & None & -6.67 & 0.00 & No \\
\hline 21 & M & 1995 & 39 & L4-L5 & 2005 & Removal & Dynesys & 62.50 & 3.33 & No \\
\hline 22 & $\mathrm{~F}$ & 2002 & 37 & L4-L5, L5-S1 & 2005 & Removal & None & 11.11 & 10.00 & No \\
\hline 23 & $\mathrm{~F}$ & 1990 & 55 & L4-L5 & 2006 & Removal & None & 14.29 & 13.97 & No \\
\hline
\end{tabular}

the left common iliac artery (in a L4-L5 case) and once a small incomplete colon lesion. These complications could all be controlled by the vascular surgeon with relatively little blood loss. Mean blood loss for the anterior procedure was $753 \mathrm{cc}(60-5,100 \mathrm{cc})$. In one patient profound bleeding was encountered from the vertebral body bone and possibly the epidural plexus underneath the distal endplate of a L5-S1 disc prosthesis. This was controlled by packing with bone bank chips and gel foam, however the total blood loss in this two-level case was 5,100 cc.

In another patient we planned to remove the disc prosthesis, however, due to a rupture of the small intestine during the access phase, we decided only to perform a posterior fusion.

\section{Preliminary clinical results}

General clinical information for both revision strategies, with a follow-up period of at least 1 year, is shown in Table 3 .
Ten patients receiving posterior fusion without removal of the prosthesis, have at this moment a follow-up period of more than 1 year since their posterior fusion. The mean VAS before posterior fusion was 8.0 (SD 0.9) and after posterior fusion 6.3 (SD 2.1) (Fig. 5).

Furthermore, 14 patients had a follow-up period of more than 1 year since their disc prosthesis removal. Two disc removal patients had insertion of the Dynesys fixation

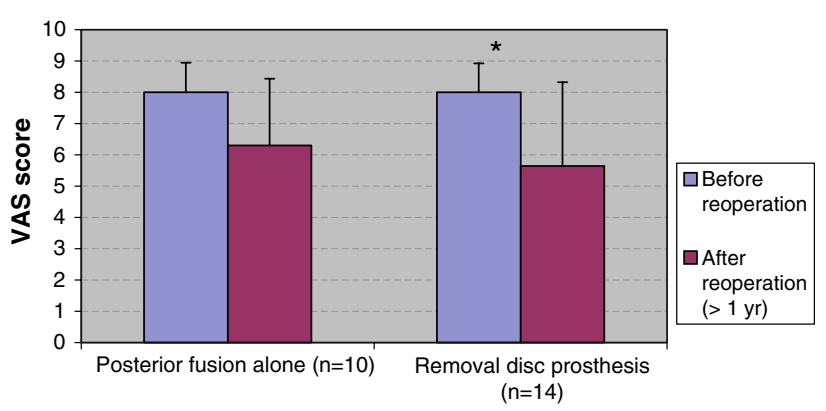

Fig. 5 VAS scores before and after salvage operation 


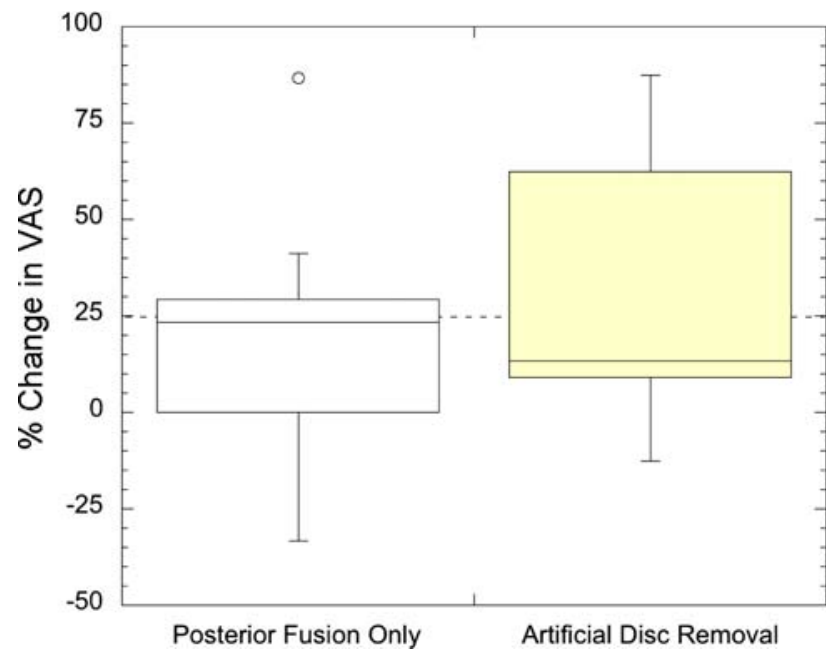

Fig. 6 Percentage change in VAS scores in both revision strategies

system (one patient had a follow-up of at least 1 year), in addition to the fused disc prosthesis level, for multiple adjacent levels degeneration. This multilevel Dynesys instrumentation was recently removed in both patients due to screw loosening. The VAS score in this group decreased significantly from 8.0 (SD 0.9) before disc prosthesis removal to 5.6 (SD 2.7) after removal $(P<0.05)$ (Fig. 5). The percentage of improvement after revision surgery in both groups is shown in Fig. 6 .

The mean Oswestry decreased in the posterior fusion group $(n=10)$ from 57.0 (SD 17.0) to 44.6 (SD 20.4), and in the disc removal group $(n=13)$ from 56.3 (SD 14.0) to 43.0 (SD 20.7) (Fig. 7). This questionnaire is missing in one patient from the disc removal group. According to the abovementioned IDE-criteria, in which an improvement of $\geq 25 \%$ was considered to be clinically improved, 3 out of 10 patients in the fusion group and 6 out of 13 patients in the disc removal group were clinically improved (Table 3; Fig. 8).

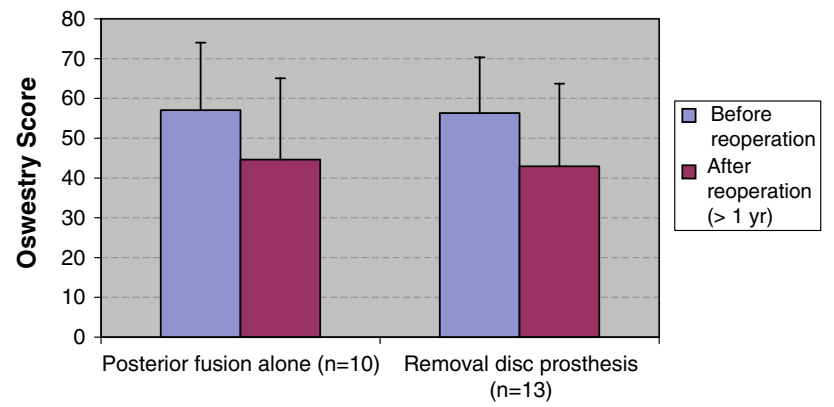

Fig. 7 Oswestry scores before and after salvage operation

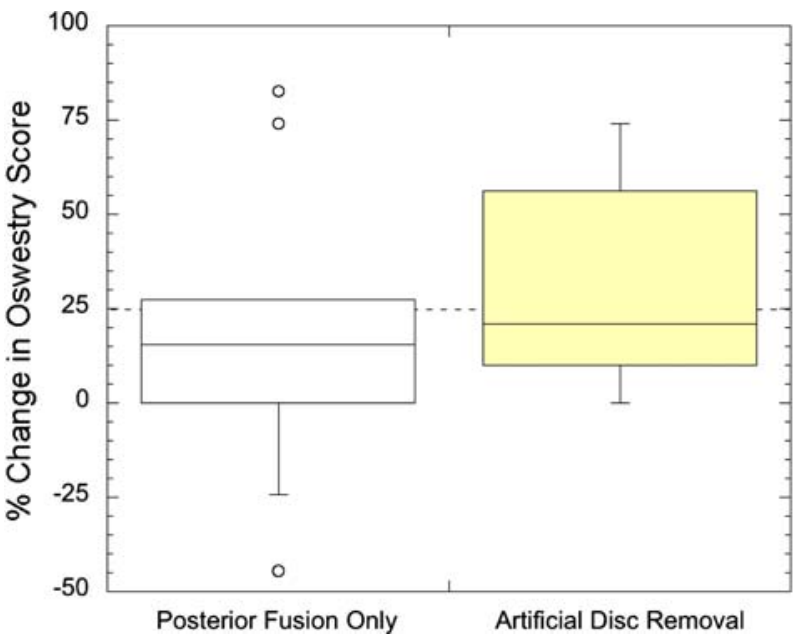

Fig. 8 Percentage change in Oswestry scores in both revision strategies

Postoperative complications

Two patients from the posterior fusion group developed pseudo-arthrosis postoperatively.

We encountered five postoperative complications in the disc removal group. One patient developed deep venous thrombosis (DVT) of the left leg after suturing a left common iliac vein lesion. In two patients, decreased sensitivity in the left groin and upper leg was noticed, which was partially reversible. Two patients have severe pain and decreased diffuse strength in the left leg postoperatively. In one of these patients these complaints are diminishing at the moment. Presumably, excessive retraction of the lumbosacral nerves in the psoas muscle played a role in these left leg complications.

\section{Discussion}

Seventy-five patients with persistent leg and back pain after insertion of SB Charite disc prosthesis were studied. The causes of persisting pain were thought to be related to the following late-complications: subsidence, migration, wear of the disc prosthesis, facet joint degeneration or adjacent degeneration in various combinations.

Good placement and good sizing of the disc prosthesis appeared problematic for many of the patients in our series. In 39 patients we saw subsidence of the disc prosthesis, and in our judgement X-rays showed that in 24 of these patients the disc prosthesis was too small. Whether suboptimal sizing and placement resulted from initial surgical technique, or from historical limitations in instrumentation and/ or sizing availability remains unclear. Fixation of the disc prosthesis can be inadequate, giving subsidence and 
migration of the disc prosthesis. Migration can probably be prevented by coating of the metal plate, but subsidence probably not.

Previous studies suggested that adjacent degeneration is prevented after disc replacing surgery [4, 8, 14]. However, in our study 36 patients showed adjacent disc degeneration. This could be the result of the DDD itself, spreading to multiple levels of the spine, and/or be the consequence of stresses on adjacent levels, generated from the unphysiological motion and functioning of the disc prosthesis.

Concerning the 25 patients in which facet joint degeneration was visible on CT-scans, we hypothesized that an instability is created after removal of the anterior longitudinal ligament and the annulus fibrosis. Replacement with an unconstrained prosthesis will accentuate this instability, especially in extension and axial rotation. The facet joints will be the only restrictor of axial rotation and will degenerate with time.

Because of persisting back and leg pain we performed a posterior fusion without disc removal in 15 patients. Initially, the results were disappointing in most patients, and we therefore started to remove the disc prosthesis. In all patients with removal of the disc prosthesis, PE wear was observed in minor or major degree with surrounding inflammatory fibrous tissue containing PE wear debris. The association between periprosthetic tissue inflammatory reactions and clinical manifestations of pain is not clear at the present time and will be studied further. It is speculated that with removal of the disc prosthesis and the inflammatory periprosthetic tissue, the patient may obtain better pain relief than after only posterior fusion [19]. This hypothesis obviously needs further support with a larger number of more carefully selected patients.

Clinical results after disc prosthesis revision performed in our hospital were diverse. Patients with short segment fusions seemed to fare better than patients with long segment fusions or long flexible fixations with the Dynesys system. At present, the small number of patients and the large number of potential factors influencing the outcomes (Table 3), precluded assessment of a significant association between revision strategy and outcome in the current study.

The mean VAS for pain after disc prosthesis removal was reduced significantly with 2.4 points, from 8.0 to 5.6, whereas the VAS in patients with posterior fusion showed a smaller decrease from 8.0 to 6.3. However, the analyses are based on a small number of cases and a greater number of patients with longer follow up are necessary for a more definitive conclusion.

In a collaborative study by Kurtz et al. [10] it was concluded that artificial discs exhibited wear mechanisms similar to artificial hips and knees. Since the operated patients are mostly between 30 and 50 years at the time of their disc implantation and these young patients will be likely very active, wear may become a clinically significant issue at long-term follow-up. The clinical relevance of wear in total disc replacements is the subject of intense, ongoing research at our institutions.

A major point to consider is that, in contrast with a posterior fusion, retrieval of an artificial disc prosthesis can be dangerous because of nearby vascular structures and scar tissue from the original surgery. However, in our hands, disc removal surgery proved feasible in all but one case in this patient group (26/27 disc retrievals, 96\%). Due to the availability of a vascular surgeon during the retrieval surgery average blood loss could be restricted.

In conclusion, serious complications may arise following total disc replacement surgery, however, as yet relatively few data are available to provide the basis for treatment of patients with clinically failed artificial discs. Removal of the disc prosthesis with anterior and posterior fusion gives slightly better results than posterior fusion alone after a follow-up of at least 1 year. Removal of the SB Charité artificial disc was feasible but with inherent risks. As more data become available, perhaps revision artificial disc surgery may become a more common operation for spine surgeons in the near future.

\section{References}

1. Bertagnoli R, Kumar S (2002) Indications for full prosthetic disc arthroplasty: a correlation of clinical outcome against a variety of indications. Eur Spine J 11(Suppl 2):S131-S136

2. Blumenthal S, McAfee PC, Guyer RD, Hochschuler SH, Geisler FH, Holt RT, Garcia R Jr, Regan JJ, Ohnmeiss DD (2005) A prospective, randomized, multicenter Food and Drug Administration investigational device exemptions study of lumbar total disc replacement with the CHARITE artificial disc versus lumbar fusion: part I: evaluation of clinical outcomes. Spine 30:15651575 (discussion E1387-1591)

3. Cinotti G, David T, Postacchini F (1996) Results of disc prosthesis after a minimum follow-up period of 2 years. Spine 21:995-1000

4. Cunningham BW, Dmitriev AE, Hu N, McAfee PC (2003) General principles of total disc replacement arthroplasty: seventeen cases in a nonhuman primate model. Spine 28:S118-S124

5. David T (2005) Revision of a Charite artificial disc 9.5 years in vivo to a new Charite artificial disc: case report and explant analysis. Eur Spine J 14:507-511

6. de Kleuver M, Oner FC, Jacobs WC (2003) Total disc replacement for chronic low back pain: background and a systematic review of the literature. Eur Spine J 12:108-116

7. Geisler FH, Blumenthal SL, Guyer RD, McAfee PC, Regan JJ, Johnson JP, Mullin B (2004) Neurological complications of lumbar artificial disc replacement and comparison of clinical results with those related to lumbar arthrodesis in the literature: results of a multicenter, prospective, randomized investigational device exemption study of Charite intervertebral disc. Invited submission from the Joint Section Meeting on Disorders of the Spine and Peripheral Nerves, March 2004. J Neurosurg Spine $1: 143-154$ 
8. Hochschuler SH, Ohnmeiss DD, Guyer RD, Blumenthal SL (2002) Artificial disc: preliminary results of a prospective study in the United States. Eur Spine J 11(Suppl 2):S106-S110

9. Kurtz SM, Peloza J, Siskey R, Villarraga ML (2005) Analysis of a retrieved polyethylene total disc replacement component. Spine J 5:344-350

10. Kurtz SM, van Ooij A, Ross R, de Waal Malefijt J, Peloza J, Ciccarelli L, Villarraga ML (2007) Polyethylene wear and rim fracture in total disc arthroplasty. Spine J 7:12-21

11. Lee CK (1988) Accelerated degeneration of the segment adjacent to a lumbar fusion. Spine 13:375-377

12. Lehmann TR, Spratt KF, Tozzi JE, Weinstein JN, Reinarz SJ, elKhoury GY, Colby H (1987) Long-term follow-up of lower lumbar fusion patients. Spine 12:97-104

13. Lemaire JP, Carrier H, Sarialiel H, Skalli W, Lavaste F (2005) Clinical and radiological outcomes with the Charite artificial disc: a 10-year minimum follow-up. J Spinal Disord Tech 18:353-359

14. Link HD (2002) History, design and biomechanics of the LINK SB Charite artificial disc. Eur Spine J 11(Suppl 2):S98-S105

15. McAfee PC, Cunningham B, Holsapple G, Adams K, Blumenthal S, Guyer RD, Dmietriev A, Maxwell JH, Regan JJ, Isaza J (2005) A prospective, randomized, multicenter Food and Drug Administration investigational device exemption study of lumbar total disc replacement with the CHARITE artificial disc versus lumbar fusion: part II: evaluation of radiographic outcomes and correlation of surgical technique accuracy with clinical outcomes. Spine 30:1576-1583 (discussion E1388-E1590)

16. Putzier M, Funk JF, Schneider SV, Gross C, Tohtz SW, Khodadadyan-Klostermann C, Perka C, Kandziora F (2006) Charite total disc replacement-clinical and radiographical results after an average follow-up of 17 years. Eur Spine J 15:183-195

17. Schlegel JD, Smith JA, Schleusener RL (1996) Lumbar motion segment pathology adjacent to thoracolumbar, lumbar, and lumbosacral fusions. Spine 21:970-981

18. Taksali S, Grauer JN, Vaccaro AR (2004) Material considerations for intervertebral disc replacement implants. Spine J 4:231S$238 \mathrm{~S}$

19. van Ooij A, Kurtz SM, Stessels F, Noten H, van Rhijn L (2007) Polyethylene wear debris and long-term clinical failure of the Charite disc prosthesis: a study of 4 patients. Spine 32:223-229

20. van Ooij A, Oner FC, Verbout AJ (2003) Complications of artificial disc replacement: a report of 27 patients with the SB Charite disc. J Spinal Disord Tech 16:369-383

21. van Tulder M, Koes B, Bombardier C (2002) Low back pain. Best Pract Res Clin Rheumatol 16:761-775

22. Zeegers WS, Bohnen LM, Laaper M, Verhaegen MJ (1999) Artificial disc replacement with the modular type SB Charite III: 2 -year results in 50 prospectively studied patients. Eur Spine J 8:210-217 